\title{
A CONCEPTUAL FRAMEWORK FOR MICRO FINANCE
}

\author{
MR. SOMASHEKAR. N
}

Assistant Professor of Commerce, Government First Grade College, Kadur, Karnataka

\begin{abstract}
With an average yearly growth rate of more than $40 \%$ and over 66.7 million clients, microfinance's significance as a development instrument is well proven. The current yearly cash requirements are projected at \$5 billion, but available donor money is believed to be less than \$1 billion. Microfinance is too hazardous for most private investors, limiting cash flow potential. Socially Responsible Investing, a $\$ 2.4$ trillion market expanding $15 \%$ yearly, is one investment segment that fits nicely with microfinance. They place a premium on the Double Bottom Line, which combines financial gain with positive social effect $(D B L)$. Institutions profit from advertising their DBL, but there are few instruments available to do so efficiently in microfinance. As a result, there is a larger focus on financial results alone. As a specialist sub-segment of microfinance, the framework is especially useful for microcredit with educational initiatives. Increased use of DBL in microfinance is a beneficial addition to industry best practices, but the concept is still in its early stages, so more voices and contributions are needed to make progress and find sustainable solutions. This paper is a conceptual paper to analyzing the concept of microfinance in development of the society with the Double Bottom Line form the study it was found that the microfinance institutions are the bone for the cash inflow in rural India and Double Bottom Line is one vehicle to foster its success
\end{abstract}

KEYWORDS: Microfinance, Double Bottom Line \& Microcredit.

Received: Jul 04, 2021; Accepted: Jul 24, 2021; Published: Aug 14, 2021; Paper Id.: IJECRDEC20213

\section{INTRODUCTION}

It's a term used in the corporate world to describe social responsibility investment and business. While all businesses have a traditional business model to monitor their capital structure - profit or loss - businesses that pursue a second bottom line measure their performance in terms of positive social influence. The monetary bottom line is combined with a second bottom line that shows the overall outcome of a social aspect.

\section{DBL Structural Framework}

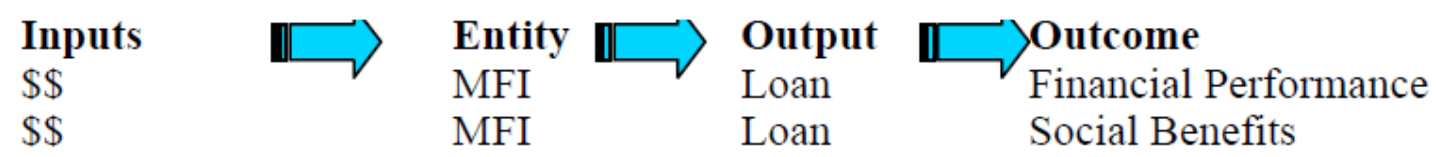

Organizations, especially MFIs, are made up of inputs, human and material resources, as well as an objective, a geographic location, and other vital characteristics that define them. Capital is a critical input for every organisation, and it usually took the form of gifts, investments, and assets for MFIs. Businesses take capital and turn it into tangible material entities, such as commodities and services. Loans made, clients served, and loan values disseminated are all instances of MFI outputs.

The aggregate and long-term effects of an organization's production are known as results. They are the direct and indirect results, products, and/or by-products produced during the conversion of inputs to outputs. It may 
be difficult to determine a link between inputs and outcomes

A sequence of concentric rings extending outwards can be considered as the universe of inputs, outputs, and outcomes. The entity is at the centre, and stakeholders are touched (or impacted) in different ways depending on their closeness. The number of persons affected by the outcome grows as you go out from the epicenter, yet the degree of the event decreases.

\section{The Business Case for Microfinance}

$(\mathrm{Pr}+\mathrm{O}) * \mathrm{P}=\mathrm{S}$ is the business 'formula' for forming a new entity that meets a requirement. When the Problem (Pr) is combined with the Opportunity $(\mathrm{O})$ and then multiplied by the Potential (P), the result is a Solution (S) (Tulchin, 2003).

Pr: The Issue Existing sources of funding are inadequate for microfinance. According to the Consultative Group to Assist the Poorest (CGAP), 20 percent of total potential demand has been met.

The Micro Credit Summit's goal of servicing 150 million people by 2015 necessitates a significant increase in onlending. While donor financing is appropriate for microfinance, it is insufficient to meet demand. Meanwhile, the global economic disparity has widened in recent generations, with rising numbers of poor people and a growing global population, posing a challenge to the UN's Millennium Development Goals.

O: The financial markets provide the opportunity. Every day, $\$ 1.8$ trillion in capital is exchanged.

The dot-com bubble shook traditional investments. International stocks, which have historically provided decent diversification, are unappealing. This environment creates opportunities for new asset classes that offer higher yields and more variety in investment portfolios.

Microfinance has enticing financial characteristics, such as yearly growth rates of more than $40 \%$, institutions that offer double-digit returns on investment (ROI), and an overall portfolio value of more than $\$ 75$ billion.

P: Microfinance requires funding, and the business environment is volatile. MFIs must target the correct audience with their business model. Microfinance also contributes to notable social successes:

In total, there are about 15,000 MFIs in nearly every country. More than 66.7 million people use MFIs. MFIs have aided in the creation of millions of jobs, the improvement of housing, and the overall alleviation of poverty.

S: Microfinance institutions are positioned as a solution for successfully evaluating and then monitoring financial and social events both as the Double Bottom Line (DBL). Microfinance is one of the few fields in development or commerce that places such a heavy emphasis on both economic and social performance.

Documenting and monitoring both lines, especially the social one, yields data that can be used for management decisions, marketing, garnering media attention, academic study, and (a highly desirable end result) investment decisionmaking.

Microfinance's superior financial and social outcomes provide it a market competitive advantage over other forms of capital. MFIs require precise methodologies to document social gains in order to achieve this objective. This role is enhanced by the industry's use of defined metrics that allow for institutional comparability and data aggregation. Tools should be simple to understand, measurements should clearly reflect accomplishments, and the process should be sensitive to MFI managers' time and budget. 
The term "Double Bottom Line" is still in its infancy, and the terms aren't consistently defined. The DBL comprises a financial bottom line as well as a second bottom line that shows the net results of a project's social features. This entails assessing social activities in the same way that financial performance is assessed. Qualitative performance reporting, management devices, quantifiable data, monetized outcomes, and indicators are all tools for conveying the second bottom line (Tulchin, Microfinance \& the Double Bottom Line, 2003).

\section{DBL \& Microfinance: Microcredit with Education}

Microcredit with Education (MwE) is an exemplary sub-segment of the industry to illustrate microfinance DBL (or movement). Freedom from Hunger uses the term "credit with education" to characterise its service delivery methodology. $\mathrm{MwE}$ is a wide term that refers to any forms of microfinance that are linked to learning endeavours, while there are various variations and levels of integration. In this DBL example, all are valid. MwE provides a consistent look and set of behaviours (Kagan, 2021).

$\mathrm{MwE}$ is an attractive value proposition. It concentrates on the economic and social needs of the underprivileged. This implies that a programme provides greater social benefits than microfinance alone, putting degree, amount, and depth aside for the time being. Successful MFIs that additionally provide education generate more "social good."

This institution has the chance to portray this dynamic in order to reflect the productivity of its programmes and to promote its qualities in order to raise funds. For both operations, the DBL is a useful tool. The above frameworks link programme activities, outcomes, and community outputs. MwE outlines the financial and other advantages. One of two themes might be emphasized by such an institution: the discounted return model or the value added model, as seen here.

\section{CONCLUSIONS}

Microfinance's image as a good development instrument has been cemented, and the next generation of MFIs must now demonstrate poverty eradication. A large number of new funding sources are required. MFIs must seek new sources of finance by aligning the main traits that set them apart from funding competitors.

By evaluating economic value, quantifying social consequences, and building links between input, output, and results, DBL serves as both a foundation framework and a measurement instrument for setting MFI apart. DBL is also favoured by socially conscious investors. MFIs are more appealing to this investor since they use consistent measurements and criteria. Microbusinesses that offer educational programmes, in particular, are highly suited to using the DBL to communicate their achievements. Microbusinesses that offer educational programmes, in particular, are highly suited to using the DBL to communicate their achievements.

These factors all contribute to microfinance institutions' primary goal of boosting cash inflows. The role of the microfinance business in society will be determined by history, but the Double Bottom Line is one way to ensure its success.

\section{REFERENCES}

1. Boschee, J. The Social Enterprise Sourcebook. Vol. 1. Northland Institute, 2001

2. Clark, C. et al. Desperately Seeking Outcomes. Summary of Double Bottom Line Project Findings for 3/03 Meeting on Social Impact Assessment. 
3. Cohen, M. \& Sebstad, Microfinance and Risk Management: A Client Perspective. CGAP Focus No. 17. Adapted from "Synthesis Report on Microfinance, Risk Management, and Poverty." 2000

4. Copestake, J. Towards a General Framework for Client Monitoring Within Microfinance Organizations. Imp-Act Learning Notes No. 5, 2001

5. Daley-Harris, S. State of the Microcredit Summit Campaign Report 2002. ILO, 2002.

6. Kagan, J. (2021, July 21). Microfinance. Retrieved August 7, 2021, from investopedia: https://www.investopedia.com/terms/m/microfinance.asp

7. Tulchin, D. (2003). Microfinance \& the Double Bottom Line. Microfinance \& the Double Bottom Line: Measuring Social Return for the Microfinance Industry \& Microcredit with Education Programs (pp. 4-12). Social enterprise. Associates.

8. Tulchin, D. (2003). Microfinance's Double Bottom Line. Retrieved August 7, 2021, from Microfinance's Double Bottom Line Social Ent $\quad$ - $\quad$ CiteSeerX: https://moam.info/microfinances-double-bottom-line-social-entciteseerx 59b932951723ddd8c6ad5c00.html

9. Hussain, Hafsa, L. Y. B. A. Shaheen, and Muhammad Ahmad Shahid. "Microfinance NGOS in Pakistan: Outreach and Sustainability." International Journal of Accounting and Financial Management Research (IJAFMR) 8.2: 17-26.

10. Beg, S. A. N. A. "Prospects, problems and potential of Islamic banking in India." International Journal of Accounting and Financial Management Research 6.3 (2016): 9-20.

11. Hque, Ubaida. "Contribution of Women Entrpreneurs in SMEs Amoung SAARC Countries." International Journal of Humanities and Social Sciences (IJHSS) 6.6.

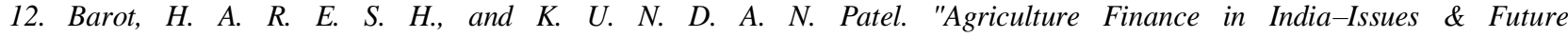
Perspectives." International Journal of Business and General Management 4.6: 5-10. 